\title{
EFEKTIFITAS PERMAINAN MONOPOLI SEBAGAI MEDIA SOSIALISASI KONSUMSI CAIRAN PADA REMAJA DI SMPN 220 JAKARTA BARAT
}

\section{EFFECTIVENESS OF MONOPOLY GAME AS A SOCIALIZATION MEDIA OF LIQUID CONSUMPTION IN TEENAGERS IN SMPN 220 WEST JAKARTA}

\author{
${ }^{1)}$ Prita Dhyani Swamilaksita, ${ }^{2)}$ Yulia Wahyuni \\ ${ }^{1,2}$ Lecturer of the Faculty of Health sciences, Nutritional Program, University of Esa Unggul \\ J1. Arjuna Utara No. 9, Kebon Jeruk, Jakarta Barat, Telp (021) 5674223 \\ ${ }^{1)}$ Email: prita.dhyani@esaunggul.ac.id
}

\begin{abstract}
ABSTRAK
Salah satu masalah gizi pada remaja adalah kurangnya konsumsi air sehingga rentan mengalami dehidrasi yang disebabkan oleh banyaknya aktifitas fisik yang menguras tenaga dan juga cairan tubuh. penyebab kurangnya konsumsi cairan adalah kurangnya pengetahuan terhadap fungsi cairan bagi tubuh. Tidak efektifnya pendidikan gizi pada remaja berdampak pada pengetahuan yang kurang pula sehingga menyebabkan perilaku makan dan minum yang salah. Oleh sebab itu, salah satu kewajiban setiap perguruan tinggi adalah menyelenggarakan kegiatan pengabdian msyarakat, yang pada kegiatan ini bertujuan utuk memberikan informasi mengenai manfaat konsumsi cairan pada remaja, meningkatkan pengetahuan, sikap dan tindakan remaja mengenai konsumsi cairan, serta mengetahui efektifitas media permainan monopoli terhadap terjadinyaperubahan pengetahuan, sikap, dan tindakan remaja terhadap konsumsi cairan. Metode yang digunakan dalam kegiatan ini adalah sosialisasi menggunakan media permainan monopoli dengan sasarannya yaitu remaja di SMPN 220 Jakarta Barat. Hasil dari kegiatan ini yaitu terjadi perubahan dan peningkatan pada pengetahuan, sikap, dan tindakan konsumsi cairan pada remaja sebelum dan sesudah kegiatan permainan monopoli sehingga dapat disimpulkan bahwa media permainan monopoli merupakan media yang efektif sebagai media pembelajaran pada usia remaja.
\end{abstract}

Kata Kunci: Konsumsi Cairan, Sosialisasi Gizi, Media Edukasi Gizi, Permainan Monopoli

\begin{abstract}
One of the problems in adolescents nutrition is the lack of water consumption, so that susceptible to dehydration caused by the amount of physical activity is strenuous and bodily fluids. The the lack of fluid intake causes the lack of knowledge on the function of body fluids. Ineffectiveness of nutrition education in adolescents impact the lack of knowledge is also causing to bad eating and drinking behavior. Therefore, one of the obligations of each college is organizing community service activities. The aim of this activity weeks to provide information about the benefits of fluid intake in adolescents, to improve knowledge, attitude, and practice regarding the liquid consumption in adolencents, and determine the effectiveness of media monopoly game against changes in knowledge, attitudes, and actions toward adolescent consumption of fluids. The method used in this activity is socialization using media monopoly game with the target is students in SMPN 220 Jakarta Barat. The results of this activity are changes and increased knowledge, attitudes, and practice in fluid consumption of adolescents before and after the game of monopoly activities, so that it can be concluded that monopoly game is an effective media as a learning media in adolescents.
\end{abstract}

Keywords: Fluid consumption, Nutritional Counseling, Media of Nutrition Education, Monopoly Game

Submited : 16 September 2016 Revision : 21 Oktober 2016 Accepted : 21 Januari 2017 
Prita Dhyani Swamilaksita \& Yulia Wahyuni

Efektifitas Permainan Monopoli Sebagai Media Sosialisasi Konsumsi Cairan Pada Remaja Di SMPN 220 Jakarta Barat

\section{PENDAHULUAN}

SMPN 220 Jakarta Barat merupakan salah satu sekolah menengah pertama yang terletak di daerah perkotaan. Golongan remaja di perkotaan merupakan salah satu segmen penting dalam masyarakat yang perlu lebih diperhatikan dari sudut perubahan konsumsi makanan dan minumannya. Selain masih dalam proses pertumbuhan dan pengenalan lingkungan, usia remaja rawan terhadap pengaruh berbagai makanan dan minuman modern.

Salah satu masalah gizi pada remaja adalah kurangnya konsumsi air sehingga rentan mengalami dehidrasi yang disebabkan oleh banyaknya aktifitas fisik yang menguras tenaga dan juga cairan tubuh. Air merupakan senyawa esensial yang keberadaannya sangat diperlukan untuk proses kehidupan. Secara normal tubuh akan kehilangan cairan melalui urin, keringat, maupun feses. Agar kondisi dan fungsi cairan tubuh tidak terganggu, kehilangan cairan tersebut harus diganti.

Apabila tubuh tidak cukup mendapatkan air atau terjadi kehilangan air sekitar 5\% dari berat badan maka tubuh akan mengalami dehidrasi. Tanda awal gejala dehidrasi adalah timbulnya rasa haus, yang dirangsang oleh peningkatan osmolalitas plasma, penurunan volum plasma atau penurunan tekanan darah.

Kebutuhan cairan tubuh tidak tercukupi, antara lain karena: tidak haus, lupa minum, merepotkan, dan malas ke kamar kecil. Sebanyak 70\% remaja minum setelah merasa haus, dan sebenarnya ini sudah terlambat karena haus merupakan indikasi awal dari dehidrasi. Sementara Bossingham et al. (2003) menyebutkan bahwa konsumsi minuman harus cukup, terutama saat musim panas agar terhindar dari dehidrasi. Berdasarkan hasil laporan Studi Diet Total 2014 Provinsi DKI
Jakarta, rerata konsumsi air remaja (13-18 tahun) di Indonesia sebesar 2.064,1 $\mathrm{ml}$ /orang/hari, meliputi air putih $1.225,1$ $\mathrm{ml}$ /orang/hari, air minum kemasan bermerek $730 \mathrm{ml} /$ orang/hari, dan minuman lainnya $78,9 \mathrm{ml} /$ orang/hari).

Hasil penelitian Stiawati (2013), menunjukan bahwa masih terdapat $14 \%$ remaja memiliki pengetahuan kurang tentang konsumsi cairan dan masih terdapat $56 \%$ remaja memiliki sikap negatif terhadap konsumsi cairan. Menurut Briawan et al (2011), masih terdapat $24,1 \%$ remaja yang asupan cairannya kurang dari 90\% kebutuhan. Mayoritas penyebab kurangnya konsumsi cairan adalah kurangnya pengetahuan terhadap fungsi cairan bagi tubuh. Tidak efektifnya pendidikan gizi pada remaja berdampak pada pengetahuan yang kurang tentang pola konsumsi makanan dan minuman yang sehat dan seimbang saat dewasa, sehingga menyebabkan perilaku yang salah. Peran media sangat besar pada proses belajar mengajar dan menjadi semakin luas serta interaktif untuk meningkatkan hasil pengetahuan siswa. Wena (2009) menyatakan bahwa media mempunyai berbagai kelebihan antara lain membuat konsep yang abstrak dan kompleks menjadi sesuatu yang nyata, sederhana, sistematis dan jelas.

Penggunaan permainan dalam hal ini monopoli sebagai media pembelajaran siswa dinilai sangat efektif untuk menumbuhkan minat siswa dalam belajar, karena selain mudah dimainkan pada hakikatnya jiwa anak adalah jiwa bermain. Pendapat serupa juga diungkapkan oleh Muhajir (2015), bahwa media bermain monopoli memberikan hiburan yang bernilai edukatif, karena dengan media itulah anak belajar.

Tujuan pengabdian masyarakat ini yaitu: 1) memberikan informasi mengenai 
Prita Dhyani Swamilaksita \& Yulia Wahyuni

Efektifitas Permainan Monopoli Sebagai Media Sosialisasi Konsumsi Cairan Pada Remaja Di SMPN 220 Jakarta Barat

manfaat konsumsi cairan pada remaja 2) meningkatkan pengetahuan, sikap dan tindakan remaja mengenai konsumsi cairan 3) Mengetahui efektifitas media permainan monopoli terhadap terjadinya perubahan pengetahuan, sikap, dan tindakan remaja terhadap konsumsi cairan.

\section{METODE}

Pelaksanaan sosialisasi mengenai konsumsi cairan pada remaja di SMPN 220 Jakarta Barat tanggal 16-23 Mei 2016 selama 1 minggu. Adapun alat bantu yang digunakan yaitu permainan monopoli yang sudah di modifikasi dengan menambahkan infromasi mengenai konsumsi cairan dan kuesioner untuk mengukur keberhasilan sosialisasi.

Sasaran pada kegiatan ini adalah remaja yakni siswa kelas VII di SMPN 220 Jakarta Barat sebanyak 49 orang dengan sebaran 24 orang laki-laki dan 25 orang perempuan.

Alur kegiatan sosialisasi terbagi atas beberapa kegiatan yaitu:

1. Seluruh peserta diminta untuk mengisi form kuesioner sebagai pre-test untuk mengukur pengetahuan, sikap, dan tindakan remaja serta konsumsi cairan harian sebelum permainan monopoli dimulai

2. Kegiatan permainan monopoli, yang terbagi atas 7 kelompok bermain

3. Seluruh peserta diminta untuk mengisi form kuesioner sebagai post-test untuk mengukur pengetahuan, sikap, dan tindakan remaja seminggu setelah kegiatan sosialisasi dilaksanakan.

Pada kegiatan ini dilakukan pula penilaian efektifitas media permainan monopoli dengan membandingkan hasil pre-test dan post-test remaja dengan menggunakan uji Paired T-test dengan alternatifnya uji Wilcoxon.

\section{HASIL DAN PEMBAHASAN}

Dari hasil pre-test diketahui bahwa $73,5 \%$ remaja memiliki pengetahuan yang kurang mengenai konsumsi cairan dan sebanyak $81,6 \%$ remaja memiliki pengetahuan baik setelah kegiatan permainan monopoli. Hasil pre-test terhadap sikap menunjukan bahwa 26,5\% remaja memiliki sikap negatif terhadap konsumsi cairan dan sebanyak 83,7\% remaja memiliki sikap positif setelah melakukan kegiatan permaian monopoli. Sedangkan, hasil pre-test terhadap tindakan menunjukan $24,5 \%$ remaja memiliki tindakan kurang terhadap konsumsi cairan dan $89,8 \%$ remaja memiliki tindakan baik terhadap konsumsi cairan setelah melakukan kegiatan permainan monopoli. Hasil rata-rata konsumsi cairan harian yang sebelum kegiatan menunjukan bahwa 65,3\% remajakurang mengkonsumsi cairan dan $89,8 \%$ remaja cukup mengkonsumsi cairan setelah kegiatan permainan monopoli dilakukan. Hasil perubahan pengetahuan, sikap, dan tindakan responden dapat dilihat pada Tabel 1 .

Tabel 1 Distribusi Pengetahuan dan Sikap Remaja mengenai Konsumsi Cairan

\begin{tabular}{|c|c|c|c|c|c|c|c|}
\hline \multirow{3}{*}{\multicolumn{2}{|c|}{$\begin{array}{l}\text { Kategori } \\
\text { Variabel }\end{array}$}} & \multicolumn{6}{|c|}{ Hasil Test } \\
\hline & & \multicolumn{3}{|c|}{ Pretest } & \multicolumn{3}{|c|}{ Posttest } \\
\hline & & $\begin{array}{c}\text { Medi } \\
\text { an }\end{array}$ & $\mathrm{n}$ & $\%$ & $\begin{array}{c}\text { Medi } \\
\text { an }\end{array}$ & $\mathrm{n}$ & $\%$ \\
\hline \multirow[t]{3}{*}{$\begin{array}{l}\text { Penget } \\
\text { ahuan }\end{array}$} & $\begin{array}{l}\text { Kura } \\
\text { ng } \\
(<60 \\
\%)\end{array}$ & - & 36 & 73,5 & - & 0 & 0 \\
\hline & $\begin{array}{l}\text { Cuku } \\
\mathrm{p} \\
(60- \\
79 \%)\end{array}$ & - & 12 & 24,5 & - & 9 & $\begin{array}{c}18, \\
4\end{array}$ \\
\hline & $\begin{array}{l}\text { Baik } \\
(\geq \\
80 \%)\end{array}$ & - & 1 & 2,0 & - & 40 & $\begin{array}{c}81, \\
6\end{array}$ \\
\hline Sikap & $\begin{array}{l}\text { Nega } \\
\text { tif } \\
\text { Posit } \\
\text { if }\end{array}$ & $\begin{array}{l}<4 \\
\geq 4\end{array}$ & $\begin{array}{l}13 \\
36\end{array}$ & $\begin{array}{l}26,5 \\
73,5\end{array}$ & $\begin{array}{l}<9 \\
\geq 9\end{array}$ & $\begin{array}{c}8 \\
41\end{array}$ & $\begin{array}{c}16, \\
3\end{array}$ \\
\hline
\end{tabular}


Prita Dhyani Swamilaksita \& Yulia Wahyuni

Efektifitas Permainan Monopoli Sebagai Media Sosialisasi Konsumsi Cairan Pada Remaja Di SMPN 220 Jakarta Barat

Pada Tabel 2 dapat dilihat rata-rata nilai pengetahuan, sikap, dan tindakan remaja sebelum kegiatan sosialisai dengan media permainan monopoli yaitu 4,27士1,688 dan mengalami perubahan setelah kegiatan permainan monopoli yaitu $8,16 \pm 0,800$. Rata-rata nilai sikap remaja sebelum kegiatan permainan monopoli adalah $4,47 \pm 1,416$, namun mengalami perubahan setelah kegiatan permainan monopoli yaitu $9,04 \pm 0,676$.

Tabel 2. Perubahan Pengetahuan dan Sikap terhadap Konsumsi Cairan

\begin{tabular}{|c|c|c|c|c|}
\hline Variabel & $\begin{array}{c}\text { Intervens } \\
\mathrm{i} \\
\end{array}$ & $\begin{array}{c}\text { Rata- } \\
\text { Rata } \pm \text { SD }\end{array}$ & $\mathrm{Z}$ & $p$ value \\
\hline \multirow[t]{2}{*}{$\begin{array}{l}\text { Pengetah } \\
\text { uan }\end{array}$} & Sebelum & $4,27 \pm 1,69$ & $\overline{-}$ & 0,000 \\
\hline & Sesudah & $8,16 \pm 0,80$ & 2 & \\
\hline \multirow[t]{2}{*}{ Sikap } & Sebelum & $4,47 \pm 1,42$ & - & \\
\hline & Sesudah & $9,04 \pm 0.68$ & 6,11 & 0,000 \\
\hline
\end{tabular}

Hasil Uji Wilcoxon didapatkan nilai $p=0,000(\alpha=0,05)$ sehingga diketahui bahwa memang terdapat perbedaan yang signifikan pada skor ratarata pengetahuan dan sikap terhadap konsumsi cairan setelah kegiatan permainan monopoli.

Berdasarkan hasil tersebut dapat diketahui bahwa media merupakan komponen yang sangat penting dalam suatu proses komunikasi. Dengan sifat unik pada tiap remaja ditambah dengan lingkungan dan pengalaman berbeda, masalah ini dapat diatasi dengan media yaitu dengan kemampuan dalam memberikan perangsang yang sama, memberikan pengalaman, menimbulkan persepsi yang sama. Monopoli dipilih karena dengan media ini dapat melatih daya ingat siswa dalam penguasaan konsep materi, melatih dan mendorong keberanian remaja untuk dapat mengungkapkan pendapatnya, dan melatih penguasaan dan pemahaman konsep materi (Edlin, 2011).
Sebuah teori menyatakan bahwa media dapat membantu tercapainya tujuan pendidikan yaitu perubahan perilaku dimana salah satunya mencakup domain sikap. Untuk mencapai tingkat efisien dan efektivitas yang memadai dalam belajar, salah satunya usaha yang perlu dilakukan adalah mengurangi sistem penyampaian bahan pelajaran yang bersifat verbalistik dengan mengembangkan media sebagai alat bantu maupun sumber belajar. Belajar dengan bermain memberikan kesempatan kepada peserta didik untuk memanipulasi, mempraktekkan, dan mendapatkan bermacam-macam konsep serta pengertian yang tidak terhitung banyaknya.

Untuk membantu terjadinya perubahan perilaku terutama dalam hal bertindak, media memiliki peranan yang sangat besar pada proses belajar mengajar. Media mempunyai berbagai kelebihan antara lain membuat konsep yang abstrak dan kompleks menjadi sesuatu yang nyata, sederhana, sistematis dan jelas. Menurut Sawka et al (1999), pengalamanpengalaman yang melibatkan penglihatan, sentuhan, rasa atau gerakan umumnya sangat jelas dalam memori kita, dan jika menyangkut lebih dari satu indera atau pengalaman akan menjadi lebih mudah diingat. Media permainan yang digunakan sebagai bahan untuk merubah perilaku memberikan kesempatan kepada remaja untuk mempraktekan dan mendapatkan bermacam-macam konsep serta pengertian yang tidak terhitung banyaknya. Media pembelajaran dengan permainan dapat merangsang untuk belajar sesuatu yang baru dan memberikan pengalaman yang menyenangkan kepada remaja.

\section{SIMPULAN}

Beberapa kesimpulan yang didapatkan dari kegiatan pengabdian masyarakat ini yaitu, terdapat perubahan yang signifikan terhadap pengetahuan, 
Prita Dhyani Swamilaksita \& Yulia Wahyuni Efektifitas Permainan Monopoli Sebagai Media Sosialisasi Konsumsi Cairan Pada Remaja Di SMPN 220 Jakarta Barat

sikap, dan tindakan konsumsi cairan pada remaja di SMPN 220 jakarta Barat setelah dilkukan sosialisasi dengan media permainan monopoli.

Media permainan monopoli ini dapat diaplikasikan sebagai suatu media yang efektif dalam proses pembelajaran untuk usia remaja yang tidak hanya memberikan informasi mengenai gizi tetapi juga informasi mengenai pembelajaran lainnya.

\section{DAFTAR PUSTAKA}

Edlin, I. (2011). Perbedaan Asupan Cairan dan Berat Jenis Urin pada Siswa Kelas V SD Negeri Semanan 11 Petang Kalideres Jakarta Barat dengan Siswa Kelas V SD Swasta Muslimat Kalideres Jakarta Barat. Karya Tulis Ilmiah. Jakarta : Poltekkes Kemenkes Jakarta II.

Stiawati, L. (2013). Pengetahuan, Sikap dan Tindakan Konsumsi Air pada Siswa-Siswi SMA PGRI 1 Bekasi. Karya Tulis Ilmiah. Jakarta : Poltekkes Kemenkes Jakarta II.

Briawan, D., Sedayu, T.R., Ekayanti, I. (2011). Kebiasaan Minum dan
Asupan Cairan di Perkotaan. Jurnal Gizi Klinik Indonesia, Vol. 8 (1) : 36-41.

Briawan, D., Hardinsyah., Marhamah., Zulaikhah., Aries, M. (2011). Konsumsi Minuman dan Preferensinya pada Remaja Di Jakarta Dan Bandung. Jurnal Gizi Indonesia, 34(1), 43-51.

Wena, M. (2009). Strategi Pembelajaran Inovatif Komputer. Jakarta: PT Bumi Aksara.

Bossingham, JM., Nadine, SC., Wyne, WC. (2005). Water Balance, Hydration Statues and Fat Free Mass Hydration In Younger and Older Adult. American Journal Clinical Nutrition. 81 : 1342-1350.

Sawka, M.N., Cheuvront, S.N., Carter, R. (2005). Human Water Needs. Nutrition Reviews Media, 63 (6), 30-9.

Muhajir. (2015). Pengembangan Permainan Monopoli Sebagai Media Pembelajaran Batik Kelas V SD Siti Aminah Surabaya. Jurnal Pendidikan Seni Rupa, Vol 3(2), 218-226. 